\title{
El mecanismo de "screening" en Europa Central. Un desafío para México ${ }^{1}$
}

The "screening" mechanism in Central Europe. A challenge for Mexico

Lukasz, Czarnecki ${ }^{2}$

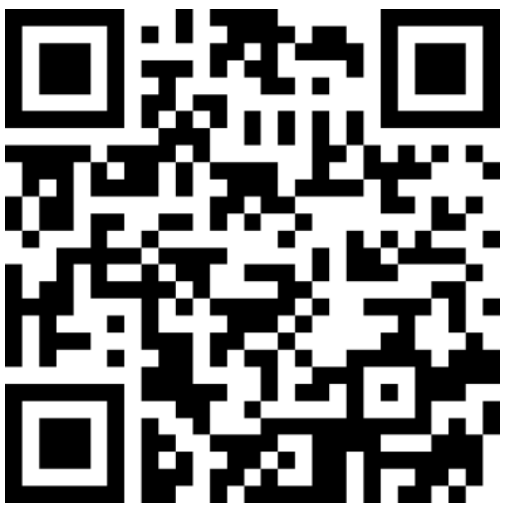

Fecha de recibido: 29-03-2021

Fecha de aceptado: 04-06-2021

\section{(cc) BY-NC-ND}

Esta obra está bajo una licencia de Creative Commons Reconocimiento-NoComercial-

SinObraDerivada 4.0 Internacional

\begin{abstract}
RESUMEN
El objetivo general del presente artículo es analizar las prácticas proteccionistas en lo referente a la Inversión Extranjera Directa introducidas en los últimos años en Europa Central, así como las implicaciones para México. Para proteger el mercado europeo de las prácticas abusivas la Unión Europea creó el mecanismo de screening a partir del Reglamento de la Unión Europea No. 2019/452 de 2019. Los países de la Europa Central implementaron en sus marcos legales dichas provisiones. ¿Cuáles son las implicaciones de esos marcos legales para la relación económica con México? Se aplicó el método comparativo en lo referente a los marcos legales, así como el análisis de los datos empíricos. Con la técnica de investigación de la revisión documental el tipo de investigación es cualitativo. En la conclusión se observa que los países de la Europa Central presentan una heterogeneidad en lo referente a la implementación de las medidas proteccionistas de la UE. Además, se considera que la perspectiva post-pandemica de la recuperación económica la cooperación será un desafío por las prácticas proteccionistas, incluyendo un desafío para México para estrechar los lazos con Europa Central. Por ende, se considera el desarrollo de campos estratégicos de mutuo beneficio en los temas de energías renovables, transporte sustentable urbano, y proyectos conjuntos a nivel municipal.
\end{abstract}

Palabras claves: Inversión extranjera, mecanismo screening, proteccionismo.

\begin{abstract}
The general objective of this article is to analyze protectionist practices in relation to Foreign Direct Investment introduced in recent years in Central Europe, as well as their implications for Mexico. To protect the European market from abusive practices, the European Union created the screening mechanism based on the European Union Regulation No. 2019/452 of 2019. The Central European countries implemented these provisions in their legal frameworks. What are the implications of these legal frameworks for the economic relationship with Mexico? The comparative method was applied with regard to legal frameworks, as well as the analysis of empirical data. With the research technique of documentary review, the type of research is qualitative. Among the main findings, it is considered that the post-pandemic perspective of economic recovery cooperation will be a challenge due to protectionist practices, including a challenge for Mexico to strengthen ties with Central Europe. Therefore, the development of strategic fields of mutual benefit is considered in the areas of renewable energy, sustainable urban transport, and joint projects at the municipal level.
\end{abstract}

Keywords: Foreign investment, protectionism, screening mechanis.

Cómo referenciar este artículo:

Czarnecki., L. (2022). El mecanismo de "screening” en Europa Central. Un desafío para México. Revista Política, Globalidad y Ciudadanía, 8(15), 114-129. https://doi.org/10.29105/pgc8.15-6

\footnotetext{
${ }^{1}$ Este artículo se preparó en respuesta a la convocatoria anunciada por la Embajada de México en Polonia en cooperación con esa Revista. Iniciado en marzo 2021 y finalizado en octubre 2021.

${ }^{2}$ Universidad Pedagógica de Cracovia, Polonia. Abogado por la Universidad Jagellona de Cracovia; colaborador con Centre for Antitrust and Regulatory Studies (CARS) de la Universidad de Varsovia.Email: lukasz.czarnecki@up.krakow.pl ; Orcid: https://orcid.org/0000-0002-0424-7188.
}

114 Revista Política, Globalidad y Ciudadanía | Vol. 8, Núm. 15, enero - junio 2022 | ISSN 2395-8448 | http://revpoliticas.uanl.mx/ 


\section{1.- INTRODUCCIÓN}

El problema central estriba en el análisis del proteccionismo europeo a partir de que la Unión Europea adoptó en 2019 la Regulación sobre screening - Reglamento de control de Inversiones Extranjeras Directas (IED) de la UE. La crisis del Covid-19 ha confirmado claramente que, para seguir siendo un área abierta a la inversión, la UE debe poder controlar quién invierte en su territorio y con qué propósito, y reaccionar cuando la inversión extranjera representa una amenaza para la seguridad y el orden público. Eso se refiere básicamente al caso chino que reformó recientemente la ley IED (Czarnecki 2020; Wenninges y Lohman, 2019). El Reglamento de control de IED de la UE, junto con mecanismos de control eficientes en los Estados miembros, debería proteger a las empresas y ciudadanos de los riesgos vinculados a la inversión extranjera, sobre todo si se trata del aumento de la inversión de China o India (Comisión Europea, 2019; Dadush et al. 2019). Es de suma importancia subrayar que este mecanismo aumentará en los próximos años, a medida que surjan nuevas amenazas y actores (Dorakh, 2020).

¿Cuáles son las implicaciones de los marcos legales para la relación económica con México? Entender la dinámica de estas nuevas regulaciones proteccionistas en la Europa Central, incluyendo el Grupo de Visegrado (Grupo de Visegrado incluye los cuatro países, a saber, Polonia, Hungría, República Checa y Eslovaquia. Fue creado en 1991 y su principal objetivo es la coordinación y cooperación internacional en temas económicos y culturales), Rumania y Bulgaria, es crucial para los inversionistas mexicanos que quieren buscar la oportunidad en esta parte del mundo (Makhavikova, 2018). Una propuesta de cambio incluye el desarrollo de los posibles mercados de inversiones. Éste sería el proyecto de cooperación en el marco del desarrollo de energías renovables, llevando a cabo proyectos conjuntos a nivel municipal en temas de Smart City y cambio climático.

El artículo se divide en tres partes, además de la introducción y conclusión, a saber: 1) IED de México y Grupo de Visegrado, 2) Principios de screening, 3) La institución de screening en la Europa Central, 4) Campos de cooperación: transporte sustentable, energías renovables y desarrollo de Smart City. 


\section{2.- FUNDAMENTO TEÓRICO}

\section{IED en México y Grupo de Visegrado}

La participación del IED para la construcción del PIB nacional en México, Polonia, República Checa, Hungría y Eslovaquia se presenta en Figura 1. México junto con el grupo países de la Europa Central son más bien los destinos de las inversiones (Figura 1) que aquellos que invierten en el extranjero (Figura 2). Los países ataren el capital, pero el porcentaje de GDP no es significante; para el 2019 sólo 2,7\% IED inflows componen GDP en México, y 1,9\% en Polonia, 3\% en Republica Checa, 0,7\% en Hungría y 2,3\% en Eslovaquia. En lo referente a outflows, 0,9 \% para México y 0,2\% para Polonia (OECD, 2020).

Figura 1.

PIB de IED inward, percentage, 2010-2019

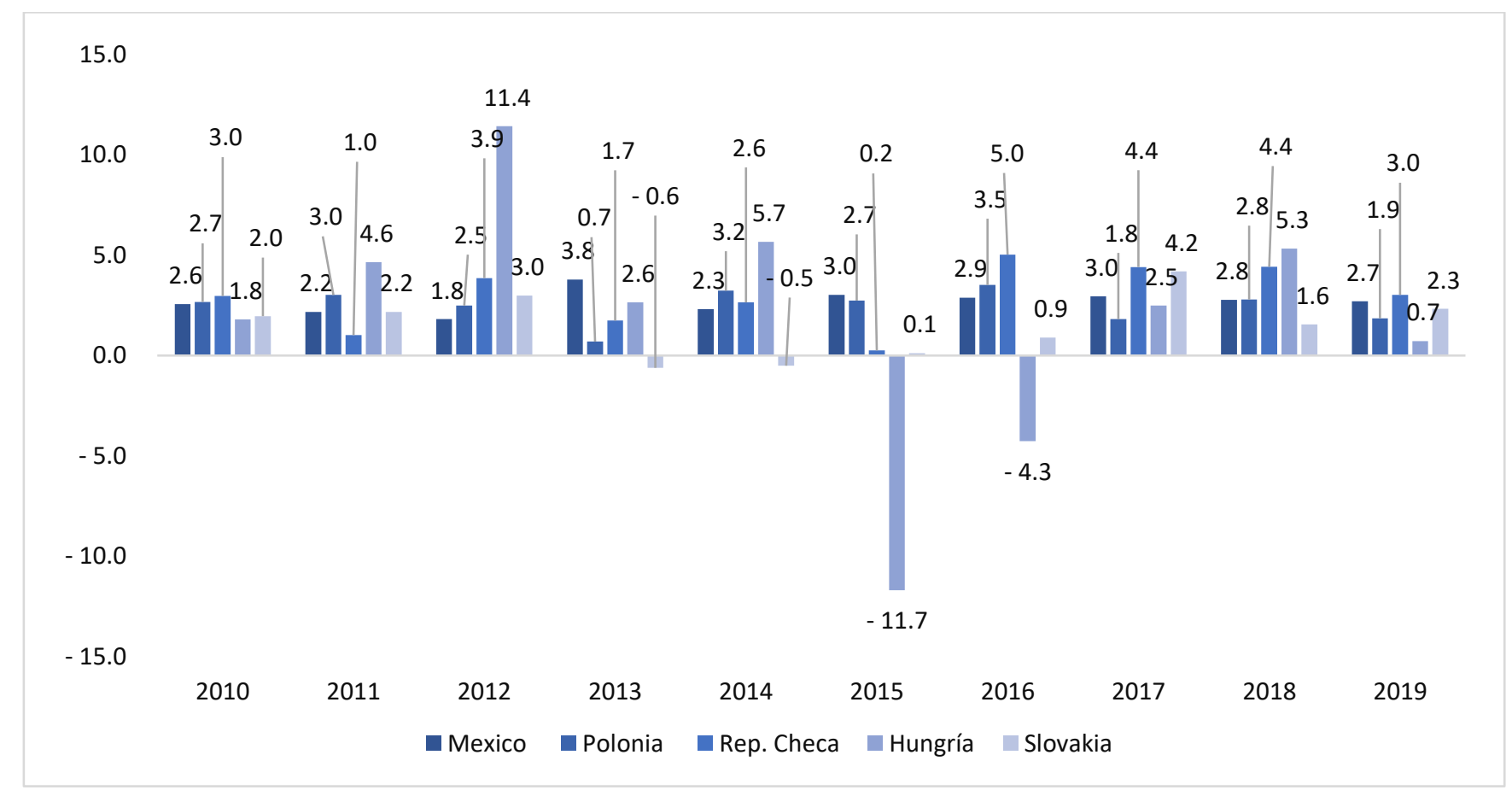

Fuente: OECD Investment statistics (2020). 
Figura 2.

PIB de IED outward, \%, 2010-2019

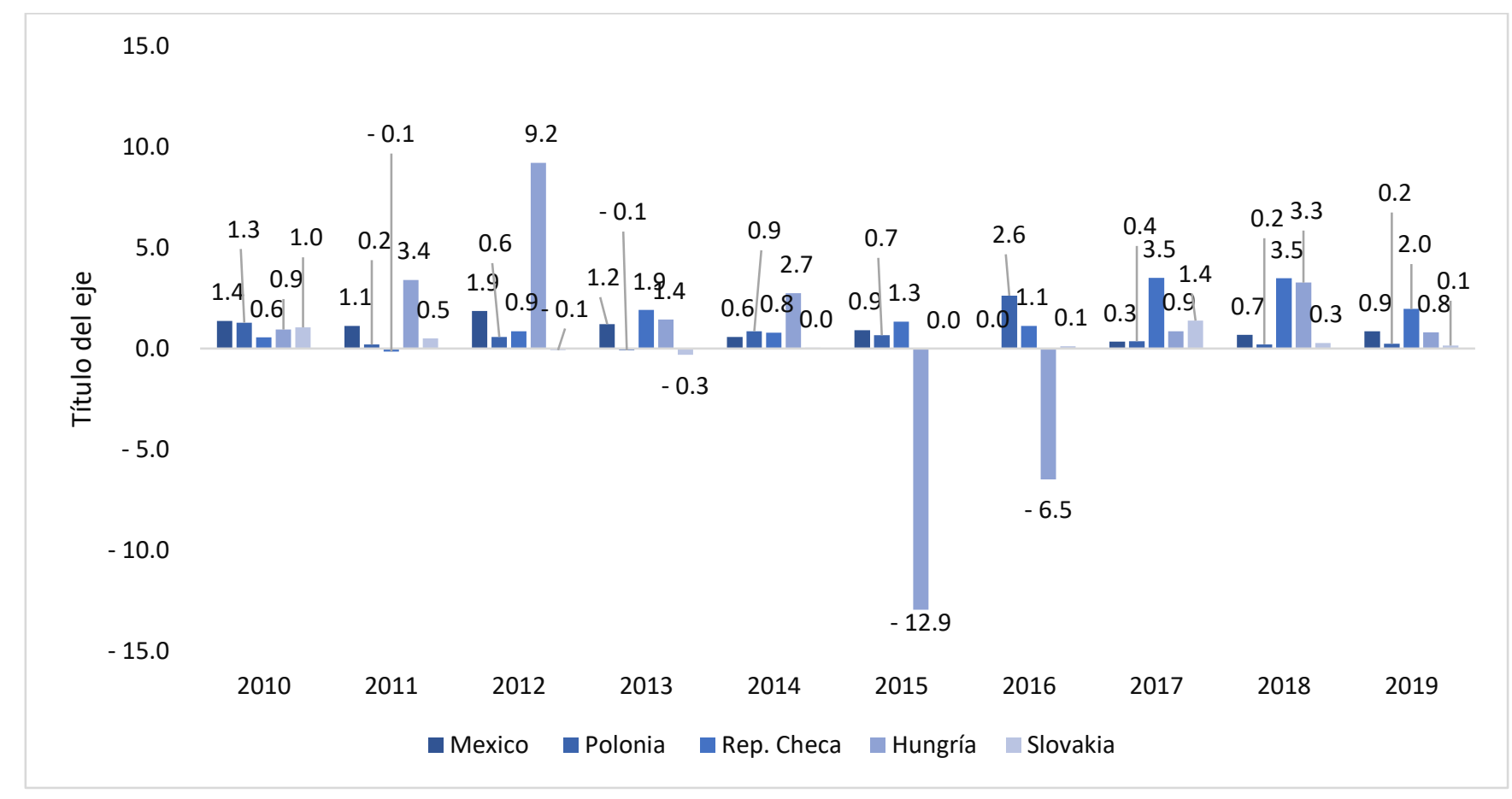

Fuente: OECD Investment statistics (2020).

En lo referente al caso de Polonia, según los datos del Banco Nacional de Polonia, IED de México a Polonia (FDI inflows) presenta fluctuaciones diversas a lo largo de una década (Figura 3), pero en términos globales, no son significantes. Además, como resultado de la crisis mundial 2008-2009 se observó la disminución de los IED en 2010. Eran cuatro años a lo largo del periodo analizado de la retirada del capital mexicano de Polonia, a saber 2010, 2013, 2016 y 2017. Sin embargo, lo que destaca es el drástico y significante retirada del capital mexicano en 2016 que alcanzó 41,3 millones de dólares. La crisis siguió en el año siguiente cuando salió la inversión por monto de 13,3 millones de dollares. 
Figura 3.

IED inflows de México a Polonia, millones de dólares (USD)

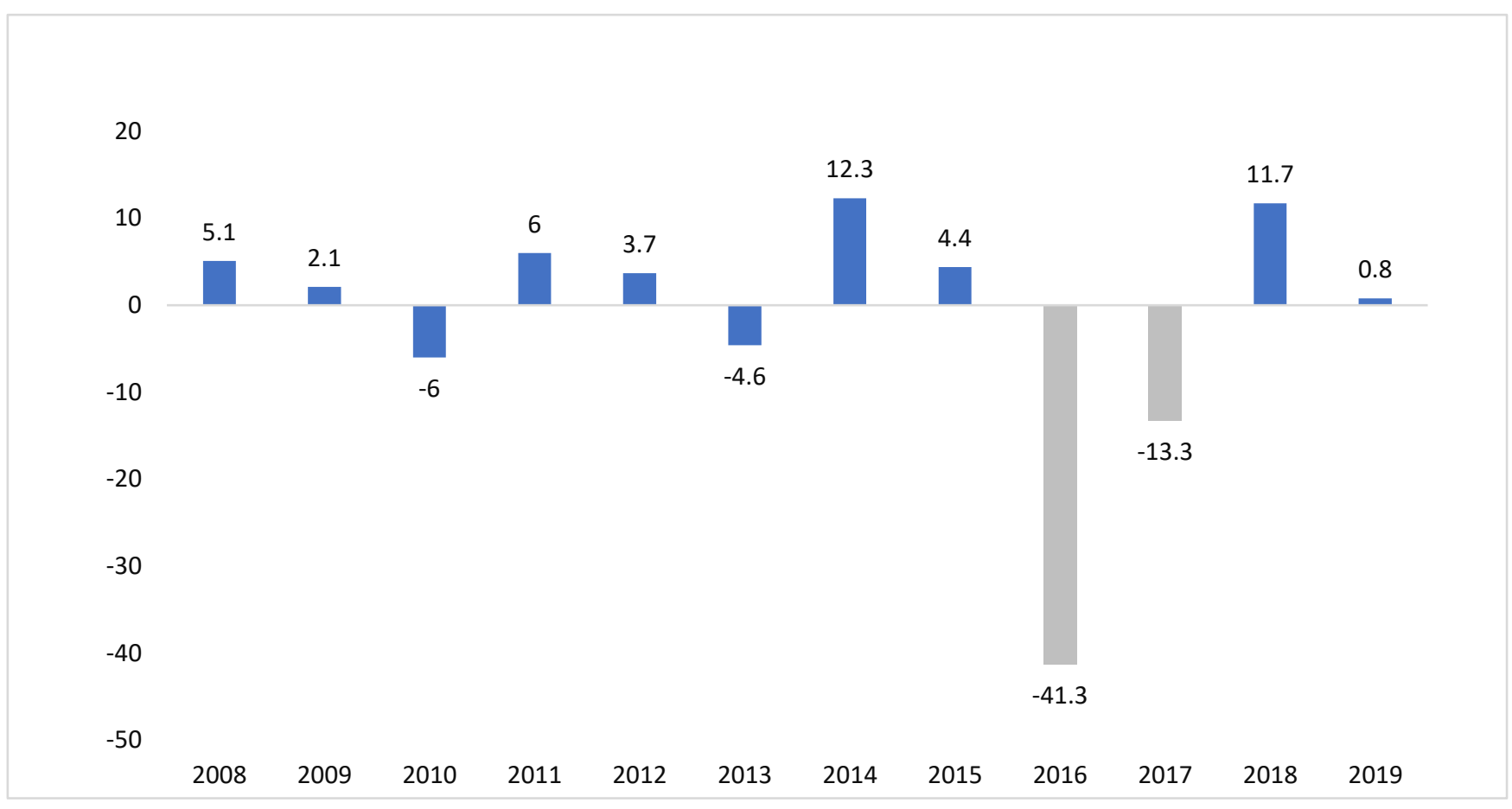

Fuente: Banco Nacional de Polonia (2020). Nota: (+) significa entradas de capital a Polonia, (-) significa la retirada de capital de Polonia, 2008-2019.

Figura 3 muestra un enorme desafío de renovar nuevos campos de cooperación entre México y Polonia. Sin embargo, el marco institucional de la Unión Europea de screening podría tener impacto negativo en los tiempos de post-pandemia. El 26 de junio de 2020 la Comisión Europea adoptó el White Paper, el documento que prevé la creación de un nuevo sistema de gobernanza económica global para desarrollar relaciones bilaterales de beneficio mutuo, protegiendo el mercado europeo de las "prácticas abusivas" (European Commission, 2020).

\section{Principios de screening}

El mecanismo de screening se consolidó con el Reglamento de la Unión Europea No. 2019/452 de 19 de marzo de 2019 que estableció el marco legal coherente para la adopción directa dentro de los marcos legales nacionales. De acuerdo con la regulación de screening: 
Los Estados miembros comunicarán a la Comisión y a los demás Estados miembros toda inversión extranjera directa en su territorio que esté siendo sometida a control.

Cuando la Comisión considere que una inversión extranjera directa objeto de control puede afectar a la seguridad o al orden público en más de un Estado miembro, o tiene información pertinente en relación con dicha inversión extranjera directa, podrá emitir un dictamen a la atención del Estado miembro que esté efectuando el control,

Si un Estado miembro considera que una inversión extranjera directa objeto de control en otro Estado miembro puede afectar a su seguridad u orden público, o tiene información pertinente en relación con dicho control, podrá formular observaciones al Estado miembro que esté efectuando el control,

Si un Estado miembro considera que una inversión extranjera directa prevista o realizada en otro Estado miembro que no esté siendo sometida a control en dicho Estado miembro puede afectar a su seguridad u orden público, o tiene información pertinente en relación con dicha inversión extranjera directa, podrá formular observaciones a ese otro Estado miembro,

Cuando la Comisión considere que una inversión extranjera directa puede afectar, por motivos de seguridad u orden público, a proyectos o programas de interés para la Unión, podrá emitir un dictamen a la atención del Estado miembro en que se haya previsto o realizado dicha inversión extranjera directa

En los ámbito de: infraestructuras críticas, ya sean físicas o virtuales, (incluidas las infraestructuras de energía, transporte, agua, sanidad, comunicaciones, medios de comunicación, tratamiento o almacenamiento de datos, aeroespacial, de defensa, electoral o financiera, y las instalaciones sensibles), así como terrenos y bienes inmuebles que sean claves para el uso de dichas infraestructuras; b) tecnologías críticas y productos de doble uso tal como se definen en el artículo 2, apartado 1, del Reglamento (CE) 428/2009 del Consejo (15), incluidas la inteligencia artificial, la robótica, los semiconductores, la ciberseguridad, las tecnologías aeroespacial, de defensa, de almacenamiento de energía, cuántica y nuclear, así como las nanotecnologías y biotecnologías; c) el suministro de insumos fundamentales, en particular energía o materias primas, así como la seguridad 
alimentaria; d) el acceso a información sensible, en particular datos personales, o la capacidad de control de dicha información, o e) la libertad y el pluralismo de los medios de comunicación (Parlamento Europeo y el Consejo de la Unión Europea, 2019).

En conclusión, se observa, el establecimiento de las medidas proteccionistas que el tiempo posterior de la pandemia serán implementadas en la Unión Europea.

\section{La institucionalización de screening en la Europa Central}

En esta parte se analiza la legislación nacional en lo referente al establecimiento del mecanismo de screening en los piases de Grupo de Visegrado, además de Rumania y Bulgaria. Las leyes se basan en el Reglamento (UE) 2019/452 del Parlamento Europeo y del Consejo de la Unión Europea Unión de 19 de marzo de 2019, por el que se establece un marco para el control de la inversión extranjera directa en la Unión Europea. El 25 de marzo de 2020, la Comisión Europea emitió una guía para los Estados miembros sobre la inversión extranjera directa y la libre circulación de capitales de terceros países y la protección de los activos estratégicos de Europa, antes de la aplicación del Reglamento. La declaración clave es que, en este momento, se requiere vigilancia, especialmente en los sectores de la salud y las industrias relacionadas, para garantizar que cualquier IED no tenga un impacto perjudicial sobre los activos de la UE. Los Estados miembros deben utilizar todas las herramientas disponibles, tanto a nivel de la UE como a nivel nacional, para evitar la pérdida de activos y tecnología cruciales, para proteger la seguridad, el orden y la salud públicos.

La comparación muestra una diferencia sustantiva en la implementación del Reglamento 2019/452 en la región; los países del Grupo de Visegrado son más avanzados en implementación las leyes proteccionistas, mientras Rumania y Bulgaria siguen con el marco menos proteccionista.

\section{República Checa}

La República Checa no cuenta con un mecanismo de screening de IED. En abril de 2020, el gobierno checo aprobó un proyecto de ley sobre la selección de inversiones extranjeras.

La versión final de la Ley de IED se adoptó el 19 de enero de 2021 y entrará en vigor el 1 de mayo de 2021 (Czech Ministry of the Interior, 2021). La autoridad competente para examinar tales inversiones sería el Ministerio de Industria y Comercio checo. 
La propuesta checa contiene un mecanismo de selección ex ante completo para las inversiones realizadas por entidades no pertenecientes a la UE. Su objetivo es introducir un requisito de notificación para inversiones en sectores específicos (equipamiento militar, infraestructuras críticas, ciberseguridad, bienes de doble uso) o cualquier otro sector si la inversión pudiera comprometer la seguridad de la República Checa o su orden público interno. El requisito se activaría si el inversor adquiere un nivel efectivo de control sobre el objetivo, como (i) al menos el 10\% de los derechos de voto de la empresa; (ii) influencia adecuada sobre la persona a través de la cual se desarrolla la actividad económica (los órganos sociales de la empresa) o (iii) dispone de los derechos de propiedad a través de los cuales se desarrolla la actividad económica.

El Ministerio checo evaluará si la inversión representa un riesgo para los intereses de seguridad o el orden interno o público de la República Checa. La evaluación de la propuesta checa podría tardar hasta 120 días a partir de la presentación de la solicitud. Una transacción sujeta al requisito de autorización será nula y sin valor si se realiza sin autorización. El incumplimiento de las disposiciones pertinentes puede exponer a los inversores a multas de hasta el $2 \%$ del volumen de negocios anual del inversor en el período contable anterior.

\section{Hungría}

El 25 de mayo de 2020, el Gobierno de Hungría adoptó un nuevo decreto sobre el control de las inversiones extranjeras en Hungría (Ministry of Justice Hungary, 2020). El nuevo régimen tiene como objetivo proteger la seguridad pública, el orden y la salud durante la pandemia, e introdujo un nuevo requisito de aprobación para las inversiones en ciertas empresas húngaras. La proyección será realizada por el Ministro de Economía Nacional. Después se emitió el decreto sobre los campos para proteger de las industrias especificas el 17 junio de 2020 (Hungarian Official Gazette, 2020). Como resultado, ahora se aplican en Hungría dos mecanismos paralelos de selección de IED. El régimen de selección de IED introducido en 2018 se limita a un ámbito mucho más estrecho de empresas y transacciones y está supervisado por el Ministro del Interior. El nuevo instrumento de evaluación estará en vigor solo hasta el 31 de diciembre de 2020.

En virtud del Decreto, las inversiones de inversores extranjeros que adquieran una participación superior a (i) el 10\% y un valor de 350 millones de HUF (aproximadamente 1 millón de euros), (ii) el 
$15 \%$, el $20 \%$ o el $50 \%$, independientemente de su valor, o (iii) $25 \%$ si es adquirido por más de un inversionista extranjero, requiere la aprobación del Ministro.

Un "inversor extranjero" es (a) una empresa u organización domiciliada en, o un ciudadano de, un estado fuera de la UE, el EEE o Suiza, o (b) una empresa u organización cuyo propietario mayoritario está domiciliado en, o un ciudadano de, un estado fuera de la UE, el EEE o Suiza. Sin embargo, ciertas adquisiciones de participación mayoritaria requieren la aprobación del Ministro si el inversor extranjero es una empresa u otra organización domiciliada en la UE, el EEE o Suiza. El Decreto se aplica a las inversiones en empresas que tienen su sede en Hungría y al mismo tiempo: son sociedades de responsabilidad limitada o sociedades anónimas privadas o públicas (cotizadas); y operan en sectores "estratégicos" especificados como la fabricación de medicamentos, dispositivos médicos u otros productos químicos, producción de combustible, telecomunicaciones, venta al por menor y al por mayor (incluidos motores y automóviles), fabricación de dispositivos electrónicos, maquinaria, acero y vehículos, industria de defensa (por ejemplo, fabricación y comercio de armas y municiones, así como tecnologías utilizadas con fines militares), generación y distribución de energía, servicios relacionados con el estado de emergencia, servicios financieros (incluidos seguros, corretaje y otros servicios), procesamiento de alimentos (incluida carne, leche, cereales, tabaco, frutas y hortalizas), agricultura, transporte y almacenamiento, construcción (incluida la producción de materiales de construcción), salud, turismo (servicios de hostelería y cafetería), entre otros.

Las inversiones sujetas al nuevo régimen requieren la aprobación del Ministro. La solicitud de dicha aprobación debe presentarse al Ministro dentro de los 10 días siguientes a la fecha de ejecución del acuerdo. Para los casos de rutina, se prevé un período de revisión de 45 días, mientras que en los casos más complejos la autoridad puede extender el período de revisión por 15 días más. El Decreto establece una obligación de suspensión, lo que significa que los inversores extranjeros pueden registrarse como accionistas en la lista de accionistas o en el libro de acciones con la aprobación del Ministro. La ejecución de una inversión que requiera la aprobación del Ministro es nula y sin valor sin dicha aprobación. Además, la propuesta prevé sanciones por incumplimiento de las disposiciones del Decreto: se puede imponer una multa de hasta el doble del valor de la transacción a las personas que estuvieran obligadas a solicitar la aprobación del Ministro. 


\section{Polonia}

Por motivo directo de la pandemia COVID-19, el 23 de julio de 2020 entraron en vigor cambios en la ley de control de la inversión extranjera directa de Polonia (Ley de 19.06.2020 (Tarcza Antykryzysowej 4.0 - Ustawa z dnia 19.06.2020, Dz. U. z 2020, poz. 1086; Act of 19 June 2020 on Subsidies on Interest on Bank Loans Granted to Entrepreneurs Affected by COVID-19 and on the Simplified Procedure for the Approval of Arrangements in Connection with COVID-19 introduced among others changes to: Act of 24 July 2015 on the Control of Certain Investments (Journal of Laws 2020, items 117, 284, and 1086). Ese marco lugar será vigente por dos próximos años hasta el 2022. Estos cambios fueron implementados dentro del existente marco legal sobre las inversiones extranjeras (Kancelaria Sejmu RP, 2015).

Nueva enmienda incluye un enfoque distinto hacia las inversiones extranjeras directas en Polonia por parte de inversores no pertenecientes a la UE (Kancelaria Sejmu RP, 2020). El control de las inversiones extranjeras se aplica a los sectores estratégicos de la economía polaca, tales como: energía, medicina, software de TI, transporte, procesamiento de alimentos y todas las sociedades anónimas que cotizan en bolsa (estas últimas independientemente de la actividad comercial). La nueva enmienda de ley polaca de IED pone bajo control estatal todas las transacciones de fusiones y adquisiciones en las que participan empresas que realizan actividades comerciales en los sectores considerados estratégicos por Polonia.

Los inversores no podrán realizar una operación de M\&A que lleve a tomar el control de una empresa considerada estratégica, sin el consentimiento previo de la autoridad competente. La nueva ley polaca de IED tendrá un impacto significativo y oneroso en las transacciones de fusiones y adquisiciones en Polonia. La nueva ley permanecerá en vigor durante dos años a partir de la fecha de su entrada en vigor, es decir, hasta el 23 de julio de 2022. El legislador polaco amplía significativamente la categoría de entidades y sectores de la economía protegidos.

La Nueva Ley de IED de Polonia establece un marco integral para el control de las actividades realizadas por personas/entidades de países no pertenecientes a la UE y no OCDE, que podrían poner en peligro la seguridad, el orden y la salud pública. La nueva ley también se interpretará como una respuesta al empeoramiento de la situación económica, causado por la pandemia del coronavirus, ya que las empresas polacas podrían ser un sujeto fácil y de bajo precio a la absorción por inversores extranjeros no pertenecientes a la UE / no OCDE. 
La Nueva Ley Polaca de IED introducirá protección contra adquisiciones por parte de entidades no pertenecientes a la UE y no OCDE. En principio, una adquisición se regirá por la Ley de IED polaca si la realizan personas o entidades no residentes en la Unión Europea o en el Espacio Económico Europeo. Sin embargo, no está del todo claro y la Ley puede interpretarse de manera diferente, si las subsidiarias de entidades no pertenecientes a la UE y no pertenecientes a la OCDE que tienen una sede registrada dentro de la UE estarán sujetas a las limitaciones establecidas por la Nueva Ley Polaca de IED. Como regla general, la permisibilidad de las limitaciones de las adquisiciones por parte de entidades de la UE está excluida por la ley europea debido a la libertad de movimiento de capitales.

La nueva ley polaca de IED se aplicará con respecto a la adquisición de una participación significativa o dominio sobre la entidad controlada, en los casos de adquisición por una persona física o entidad, siempre que se cumplan los siguientes criterios de nacionalidad: en el caso de una persona física, dicha persona no es ciudadano de ningún Estado miembro, y en el caso de entidades distintas de las personas físicas, dicha entidad no tendrá domicilio social en el territorio de un Estado miembro durante al menos dos años a partir de la fecha anterior a la notificación.

Se entenderá por Estado miembro un Estado miembro de la Unión Europea, del Espacio Económico Europeo y de la Organización de Cooperación y Desarrollo Económicos. Como se mencionó anteriormente, con respecto a los criterios de nacionalidad aplicables a la entidad, surge la pregunta de si una sede registrada dentro de la UE se mantuvo durante al menos dos años antes de la notificación pertinente por parte de una entidad adquirente, cuyo accionista final y / o beneficiario final sea una entidad que no tenga una sede registrada en la UE o una persona física que no sea ciudadano de la UE, quedará bajo el escrutinio del control polaco de IED.

En conclusión, el Parlamento polaco adoptó una legislación que modifica la Ley de 24 de julio de 2015 sobre el control de determinadas inversiones, introduciendo así un control total de las inversiones extranjeras directas en Polonia. La nueva ley entró en vigor el 24 de julio de 2020, pero ésta no va a restringir el flujo de capital de México, ya establece un marco legal para los países no pertenecientes a la OCDE. 


\section{Romania}

En Rumania, a diferencia de los países del Grupo de Visegrado, no se establecieron las reglas especiales después del Reglamento europeo de 2019. En el régimen de IED, con el fundamento de la ley de 1996, se encuentra un papel importante a la autoridad nacional, el Consejo Rumano de Competencia (RCC).

Bajo el actual régimen de selección de IED, la RCC tiene el deber de informar al Consejo Supremo de Defensa del Estado (SCSD) cualquier concentración económica notificada que pueda representar un riesgo para la seguridad nacional (Consiliul Concurentei Romania, 1996). Si la SCSD confirma la existencia de tales riesgos, recomendará al Gobierno la prohibición de la concentración notificada, lo que efectivamente pondría fin al procedimiento de control de concentraciones administrado por la RCC. Según las enmiendas propuestas, el RCC será designado como punto de contacto en virtud del artículo 11 del Reglamento de selección de IED de la UE. Las competencias de selección de IED se transferirán de la SCSD a la recién creada Comisión para la selección de inversiones extranjeras directas (CSFDI), que incluirá representantes de diversas autoridades estatales, incluida la RCC. El RCC servirá como secretaría del CSFDI sin tener derecho a voto en las reuniones del SCFDI. Remitirá a la SCFDI todas las notificaciones relativas a la IED en determinados sectores siempre que el valor de la IED alcance los 2 millones de euros.

\section{Bulgaria}

A la excepción de los demás países de la región, Bulgaria otorga trato nacional a los inversores extranjeros y no existen límites generales a la propiedad o el control de empresas por parte de extranjeros, ni tampoco se examinan7 ni se restringen las inversiones extranjeras en Bulgaria. A modo de excepción, la Ley de Sociedades Extranjeras de 20148 enumera 27 actividades prohibidas para los negocios por empresas registradas en paraísos fiscales y las entidades bajo su control, pero también establece una serie de excepciones. También existen restricciones específicas sobre las inversiones extranjeras en la industria del juego en virtud de la Ley de Juegos de Azar de 201210 y con respecto a la adquisición de tierras agrícolas en virtud de la Ley de Propiedad y Uso de Tierras Agrícolas de 1991.11 Sin embargo, estas restricciones se aplican básicamente a países que no son miembros del Espacio Económico Europeo (EEE) o la UE. Las restricciones reglamentarias sobre las actividades comerciales, como los requisitos de licencias, registros y permisos a veces implican el registro corporativo según las leyes de Bulgaria u 
otro Estado miembro de la UE o del EEE, pero esto no es en sí mismo un obstáculo para la inversión porque los inversores extranjeros son libres de incorporarse o participar Empresas búlgaras.

Campos de cooperación: energías renovables y desarrollo de Smart City

A pesar de las regulaciones screening la nueva realidad post-pandemica abre nuevas perspectivas del desarrollo. Por ejemplo, en el marco de energías renovables recientemente se adoptó en Polonia la ley de 17 de diciembre de 2020, sobre la promoción de la generación de electricidad en las granjas marinas de energía eólica. Los objetivos de la ley son: 1) crear reglas y condiciones para brindar apoyo a la electricidad generada en granjas eólicas marinas; 2) preparar los términos y condiciones para la implementación de inversiones en la construcción de parques eólicos, y 3) crear requisitos para la construcción, operación y desmantelamiento de granjas eólicas. A la luz de la política energética del Acuerdo de París (2015) y de la política de la Unión Europea, Polonia implementó en forma express la ley (Sejm, 2020) que permite que hasta 2040 se construirán granjas eólicas marinas que generen más de 10 GW de energía en la zona económica exclusiva del mar Báltico (Czarnecki, 2021).

Por otra parte, las ciudades se convierten en los centros urbanas que atraen a los habitantes; los flujos migratorios requieren un cambio de las políticas dinámicas hacia las ciudades inteligentes de cooperación cultural, cambio sustentable, nuevas formas de cooperación económica urbana. La denominación Smart City abre nuevas posibilidades del desarrollo local, sobre todo en el campo de infraestructura. Tal es la importancia de estrechar las relaciones entre municipios de México y los países de Europa Central.

\section{3.- MÉTODO}

La propuesta metodológica de la presente investigación tiene un ámbito multidimensional, que pretende abordar diversos elementos conceptuales operativos sobre el procedimiento de screening. Para determinar los diversos vocablos operativos se pretende implementar el método comparativo entre diversos instrumentos legales. Se utilizará el método analítico sintético, empírico y exegético partiendo de la experiencia del autor en los diversos métodos y de la experiencia para la elaboración y clasificación de los vocablos operativos en lo referente al IED. 


\section{4.- CONCLUSIÓN}

El impacto económico que tendrá México en futuros relaciones económicas dependerá del análisis no solamente de los marcos legales pertinentes al screening, pero también de la situación de la cooperación entre la Unión Europea y México (Comisión Europea, 2018).

Sin embargo, desde que entró en vigor en abril de 2019 el Reglamento de selección de la inversión extranjera directa (IED) de la UE (Reglamento 2019/452) para proteger la seguridad o el orden público, los Estados miembros han tendido cada vez más a reformar la inversión extranjera (directa) para proteger industrias estratégicas y negocios de adquisiciones oportunistas por parte de inversionistas extranjeros. Esa política proteccionista comenzó a desarrollarse en varios países a la par.

Si bien la pandemia de Covid-19 ha intensificado la consideración de este tema, los gobiernos nacionales tomaron medidas para endurecer los controles de inversión extranjera antes del brote global. En Europa Central se observa una significante diferenciación entre las medidas. Sin embargo, existen diferencias sustanciales entre los marcos legales en la región. Los países implementan nuevas leyes más estrictas (Checa, Hungría), cambian existentes (Polonia) o no implementan las medidas especiales (Bulgaria, Rumania). Para México es de suma importancia entender el contexto de mayor proteccionismo con el fin de crear un sistema de cooperación e intercambio. Como respuestas a los interrogantes y al objetivo planteado del dicho escrito se recomienda investigaciones futuras acerca del impacto del marco legal europeo para los sectores específicos del IED en el intercambio mutuo entre México y Europa Central.

\section{REFERENCIAS}

Comisión Europea, (2018). (21 of April 2018). EU and Mexico reach new agreement on trade. https://trade.ec.europa.eu/doclib/press/index.cfm?id=1830

Comisión Europea, (2019). (12 of April 2019). Screening of foreign direct investment. https://trade.ec.europa.eu/doclib/press/index.cfm?id=2006

Consiliul Concurentei Romania (1996). (21 of April 10th 1996). Law of competition Republished and

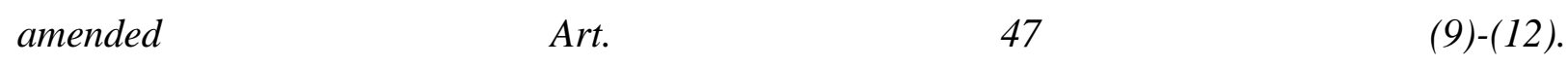
http://www.consiliulconcurentei.ro/uploads/docs/concurenta/LEGEA_CONCURENTEI_Nr_21 _eng_rev_1.pdf 
Czech Ministry of the Interior (2021). Act No. 34/2021 Coll on screening of foreign direct investments: https://aplikace.mvcr.cz/sbirkazakonu/SearchResult.aspx?q=34/2021\&typeLaw=zakon\&what= Cislo_zakona_smlouvy

Czarnecki, L. (2021). Las granjas marinas de energía eólica en el mar Báltico. ¿Nuevas oportunidades de inversión para México?Hechos y Derechos, (61). https://revistas.juridicas.unam.mx/index.php/hechos-yderechos/article/view/15386/16429

Czarnecki, L. (2020). The 2020 Foreign Investment Law of China: Confucianism and New Challenges for Social Development, Contemporary Central \& East European Law, nr 1, s. 94-103. p-ISSN: 0070-7325. DOI: $10.37232 /$ cceel.2019.08

Dorakh, A. (2020). A Gravity Model Analysis of FDI across EU Member States. Journal of Economic Integration, 35(3), 426-456. doi:10.2307/26927873

Dadush, U., Domínguez-Jiménez, M., \& Gao, T. (2019). (Rep.). The State of China-European Union Economic Relations, Brueghel. doi:10.2307/resrep28517

European Commission (2020). (Junio 17). White Paper on levelling the playing field as regards foreign subsidies.

https://ec.europa.eu/competition/international/overview/foreign_subsidies_white_paper.pdf

Hungarian Official Gazette (2020). Government Decree 289/2020 (VI. 17.) defining the measures required for the economic protection of companies having their seats in Hungary. https://trade.ec.europa.eu/doclib/docs/2020/july/tradoc_158834.pdf

Kancelaria Sejmu RP (2015). Ley de 24.07.2015. Ustawa z dnia 24 lipca 2015 r. o kontroli niektórych inwestycji. http://isap.sejm.gov.pl/isap.nsf/DocDetails.xsp?id=WDU20150001272

Kancelaria Sejmu RP (2020). Ley de 19.06.2020. Tarcza Antykryzysowej 4.0 - Ustawa z dnia 19.06.2020, $\begin{array}{llllll}D z . & \text { U. } & z & \text { 2020, } & 1086 .\end{array}$ https://isap.sejm.gov.pl/isap.nsf/DocDetails.xsp?id=WDU20200001086

Makhavikova, H. (2018), Determinants of FDI in Central and Eastern Europe: The Effects of Integration into the European Union, Springer International Publishing.

Ministry of Justice Hungary (2020). Decree no. 227/2020 concerning the necessary measures for the protection of companies seated in Hungary (2020), 25.05.2020. https://www.flandersinvestmentandtrade.com/export/sites/trade/files/attachments/2272020_V.2 5GovernmentDecreeHungary.pdf 
National Bank of Poland - NBP (2020). Foreign Direct Investment in Poland. https://www.nbp.pl/homen.aspx?f=/en/publikacje/ziben/ziben.html

Office European Union (2020). (25.03.2020). Orientaciones dirigidas a los Estados miembros en relación con las inversiones extranjeras directas y la libre circulación de capitales de terceros países, así como la protección de los activos estratégicos de Europa, antes de la aplicación del Reglamento (UE) 2019/452 (Reglamento para el control de las inversiones extranjeras directas), 2020/C $99 \quad$ I/O1. https://eurlex.europa.eu/legalcontent/ES/TXT/HTML/?uri=OJ:C:2020:099I:FULL\&from=EN

Sejm (2020). Ustawa z dnia 17 grudnia 2020 r. o promowaniu wytwarzania energii elektrycznej $w$ morskich farmach wiatrowych. http://orka.sejm.gov.pl/opinie9.nsf/nazwa/809_u/\$file/809_u.pdf.

Parlamento Europeo y el Consejo de la Unión Europea (2019, 19 de marzo). Regulation (EU) 2019/452 of the European Parliament and of the Council (Art. 6(1), 6(3), 6(2), 7(1), 8(1). https://eurlex.europa.eu/eli/reg/2019/452/oj

Wenninges, T. y Lohman, W. (2019). Chinese FDI in the EU and the US: Simple Rules for Turbulent Times. Springer Singapore; Palgrave Macmillan. 